\title{
MULTI-CRITERIA GIS ANALYSES WITH THE USE OF UAVS FOR THE NEEDS OF SPATIAL PLANNING
}

\author{
D. Zawieska ${ }^{\mathrm{a}}$, J. Markiewicz ${ }^{\mathrm{a},}$, A. Turek ${ }^{\mathrm{b}}$, K. Bakuła ${ }^{\mathrm{a}}$, M. Kowalczyk ${ }^{\mathrm{a}}$, Z. Kurczyński ${ }^{\mathrm{a}}$, W. Ostrowski ${ }^{\mathrm{a}}$, P. Podlasiak $^{\mathrm{a}}$
}

\author{
${ }^{a}$ Warsaw University of Technology, Faculty of Geodesy and Cartography, \\ Department of Photogrammetry, Remote Sensing and Spatial Information Systems, Warsaw, Poland \\ (d.zawieska, j.markiewicz, k.bakula, m.kowalczyk, z.kurczynski, w.ostrowski, p.podlasiak)@ gik.pw.edu.pl \\ ${ }^{\mathrm{b}}$ Warsaw University of Technology, Faculty of Geodesy and Cartography, Chair of Spatial Management and Environmental Science \\ a.turek@gik.pw.edu.pl
}

Commission ICWG I/Vb

KEY WORDS: UAV, Spatial Analyses, Planning System, Monitoring of Changes in Space

\begin{abstract}
:
Utilization of Unmanned Aerial Systems (UAVs) in agriculture, forestry, or other environmental contexts has recently become common. However, in the case of spatial planning, the role of UAVs still seems to be underestimated. At present, sections of municipal development use UAVs mainly for promotional purposes (films, folders, brochures, etc.). The use of UAVs for spatial management provides results, first of all, in the form of savings in human resources and time; however, more frequently, it is also connected with financial savings (given the decreasing cost of UAVs and photogrammetric software). The performed research presented here relates to the possibilities of using UAVs to update planning documents, and, in particular, to update the study of conditions and directions of spatial management and preparation of local plans for physical management. Based on acquired photographs with a resolution of $3 \mathrm{~cm}$, a cloud of points is generated, as well as 3D models and the true orthophotomap. These data allow multi-criteria spatial analyses. Additionally, directions of development and changes in physical management are analysed for the given area.
\end{abstract}

\section{INTRODUCTION}

The spatial planning system is often organized in a hierarchical structure. Common to all levels is the goal of spatial arrangement and the implementation of basic objectives of spatial policy in cities. Decisions are made at each of three levels (national, regional and local), which must support decisions made at the superior level, which are also assigned to higher implementation priorities. The key elements of the spatial planning system are documents approved at the local (municipal) level, including, first of all, local spatial plans adopted by municipal councils. Within the administrative borders of a municipality, studies of conditions and directions of spatial management are also developed; these determine, in general, local spatial policy and management rules.

Preparation of such studies is obligatory for all municipalities. The local plan is adopted by the municipal council according to local law. The Spatial Planning and Development Act of 2003 specifies binding land destinations and public investments, and determines ways of management and forms of land development. However, the Act includes many regulations which enable spatial development of municipalities without any plans. The ability to issue administrative decisions has been introduced for municipalities; these decisions concerns conditions of public investments locations and development of other investments for the areas which are covered by a local plan (Chmielewski, 2010; Spatial Planning and Development Act, 2003). Such activities support the development of a negative process of suburbanization, which is spontaneously developing in Poland and is seldom controlled by local government authorities (Zimnicka et al., 2007).

\footnotetext{
* Corresponding author
}

As a result, village settlement units, in particular those which are located directly in influence of a city zone, lose their social, economic, and landscape identity. Cultural discontinuities of spatial systems and architectural forms are observed; thus, spatial disorder develops. New built-up areas are appearing on formerly arable lands, which are unreasonably divided. In Poland, suburbanization is characterized among other things by the extreme disorder of built-up areas, disproportional development of built-up areas, technical infrastructure and transport networks, insufficient development of services within suburban zones, devastation of landscapes, aesthetically unpleasing buildings, and a rural-urban fringe (Zuziak, 2005). The negative ecological dimensions of uncontrolled suburbanization have often been stressed (Degórska, 2005). It is considered to be connected with degradation of legally protected areas, reduction of natural space of high recreational value, exclusion of fertile lands from agricultural use, and disappearing natural internal relations at the city-regional level. Contemporary photogrammetric techniques allow generation of high-accuracy metric products. Such methods allow data to be acquired for large areas within a relatively short time; this allows fast updating and verification of existing datasets. An additional important advantage of using photogrammetric data in combination with GIS processing for spatial planning purposes is the possibility of achieving readable visualizations of spatial phenomena and changes which occur in specified areas (Markiewicz and Turek, 2013,2014). Due to the complexity and big datasets, the decision-making process in spatial planning may - and should - be supported by data from UAVs and the use of GIS software tools and applications. This concerns, first of all, spatial analyses which are performed in the context of space management processes. Data acquired with 
low-altitude photogrammetry are comparable with large-format aerial photogrammetry (Bakuła and Ostrowski, 2013).

Images from UAVs can be utilized for more than the identification of existing development or analysis of changes. When used by local government officials, they may become a tool to simplify the detailed diagnosis of development areas, thus helping to counteract negative trends such as suburbanization.

\section{MULTI-SOURCE DATA IN SPATIAL PLANNING}

Apart from analysis of the current status and changes in land development, the goal of spatial analyses based on UAV data is also to generate multi-variant planning solutions and model change scenarios. Images acquired by UAVs allow fast analysis of the timeliness of studies of large areas. For this area, the Study is being developed for the entire municipality. The use of UAV data will positively influence the efficiency of the work.

The use of GIS software and integration of data from different sources acquired at different times allows fast updating of land development data (i.e., identification of land use, control of land development changes) and numerous spatial analyses. These include determination of the optimum heights of structures and the optimum location of investments (land suitability analysis), detailed analysis of the shadings of objects and terrain, determination of areas excluded from development, determination of distances to protected objects and areas, determination of possible crossings with ecological corridors, determination of zones of noise, analysis of areas threatened by floods, visibility of areas and objects, and terrain relief analysis (slopes, inclinations), up to multi-criteria analysis of the location of buildings and visualization of different ways of implementing investments (as a tool of community participation)

\section{DESCRIPTION OF PERFORMED ANALYSES}

Flights over Podkampinos Village were carried out for the data collection: this village is located in the Municipality of Kampinos, Warsaw West District, Mazovia Voivodship. Basic analyses were performed for locating new buildings, verifying the efficiency of the locations of existing structures, and supporting the generation of local plans and planning decisions. The performed analyses included:

1) land cover analyses (based on classification of a point cloud acquired from dense image matching);

2) analysis of existing buildings - identification of functions, number of floors, and types of roof (trueortho with $3 \mathrm{~cm}$ GSD, 3D mesh model);

3) identification of areas excluded from development, e.g., wetlands (based on UAV images);

4) identification of areas of planned development of spatial management (based on the Study of Conditions and Directions of Spatial Management of Kampinos Municipality);

5) identification of areas planned for single-family houses (based on the Study of Conditions and Directions of Spatial Management of Kampinos Municipality);

6) identification of areas of high natural value, areas protected by law, and areas of cultural heritage (based on the Study of Conditions and Directions of Spatial Management of Kampinos Municipality);

7) analysis of division of parcels - identification of areas planned for development (the register of lands and buildings);

8) the resulting map - areas excluded from development.

\subsection{Products obtained with the UAV data}

Colour photographs of the area were acquired by means of a Sony Alfa 7R camera with an FE 2/28 lens and a CMOS sensor of size $35.8 \times 23.9 \mathrm{~mm}$ and resolution $36 \mathrm{MP}$ (7380 x 4912 pixels) mounted on a fixed-wing platform. Photographs of the field resolution of $3 \mathrm{~cm}$ were acquired, with $80 \%$ forward overlap and $q=60 \%$ lateral overlap. In total, 1660 photographs were taken to cover the area. Photographs were processed using Pix4D Mapper software (Stretcha, 2011). Due to the low accuracy of the flight trajectory (at the level of $10 \mathrm{~m}$ ), considering the need for orientation of photographs, complete photogrammetric control was established in the test area, which consisted of 22 points. The points were surveyed using RTK technology, with the surveying accuracy $X Y=0.035 \mathrm{~m}$ $\mathrm{H}=0.05 \mathrm{~m}$. Twelve points were utilized as control points and 10 as check points.

Oriented photographs were used to create the point cloud, whose average density was 206 points per cubic metre. The point cloud was classified using LasTools (automatic classification) and ArcGIS software (manual correction of classification). Four classes were determined: ground, low vegetation, high vegetation, and buildings. The point cloud was used subsequently to generate the digital surface model (DSM) and digital terrain model (DTM). Finally, an orthophotomap of $3 \mathrm{~cm}$ resolution was generated using the DSM to orthogonalize the oriented images. Such orthoimages look very similar to the true orthophotomap (Kowalczyk et al., 2010) due to the use of a high-resolution surface model.

\subsection{Tests and spatial analyses based on multi-source data}

As mentioned in the Introduction, the basic planning tools at the local level include the local plan and decisions concerning the conditions of development. However, the basic planning document for the analysed area is the Study of Conditions and Directions of Spatial Management of Kampinos Municipality. This document was created in 2008; therefore, the municipal authorities decided to evaluate its impact. One local plan of spatial development exists in the analysed village, which covers a relatively small area. Areas where it is "planned to prepare the local plan of spatial development" have been determined. Where the local plan is missing, or where it is planned to issue a decision on conditions of development, an investment must meet the "good neighbourhood" criteria. Thus, the analysis of surrounding areas must be performed before the decision is issued, in order to specify the conditions (Chmielewski, 2010). The described analyses are performed on the basic map; however, the use of UAV photographs for these purposes may streamline such analyses and focus attention on many details which are important from the urban perspective.

The authors focused their attention on the analyses required for updating the Study. The basic analyses were performed that would be most relevant in the decision on conditions of development, and when local plans of spatial development are prepared. The possibilities of developing areas within the village were also considered.

Analysis of a specified area commenced with the determination of the area's general characteristics, and then particular parts of the analysed area were investigated in detail. In order to determine the general function of the area, based on the point cloud acquired from dense image matching, classification was performed with the use of LAS Tools. At the first stage, the class of lands was distinguished; then, the remaining points were divided into high vegetation and buildings. This operation was performed automatically. 


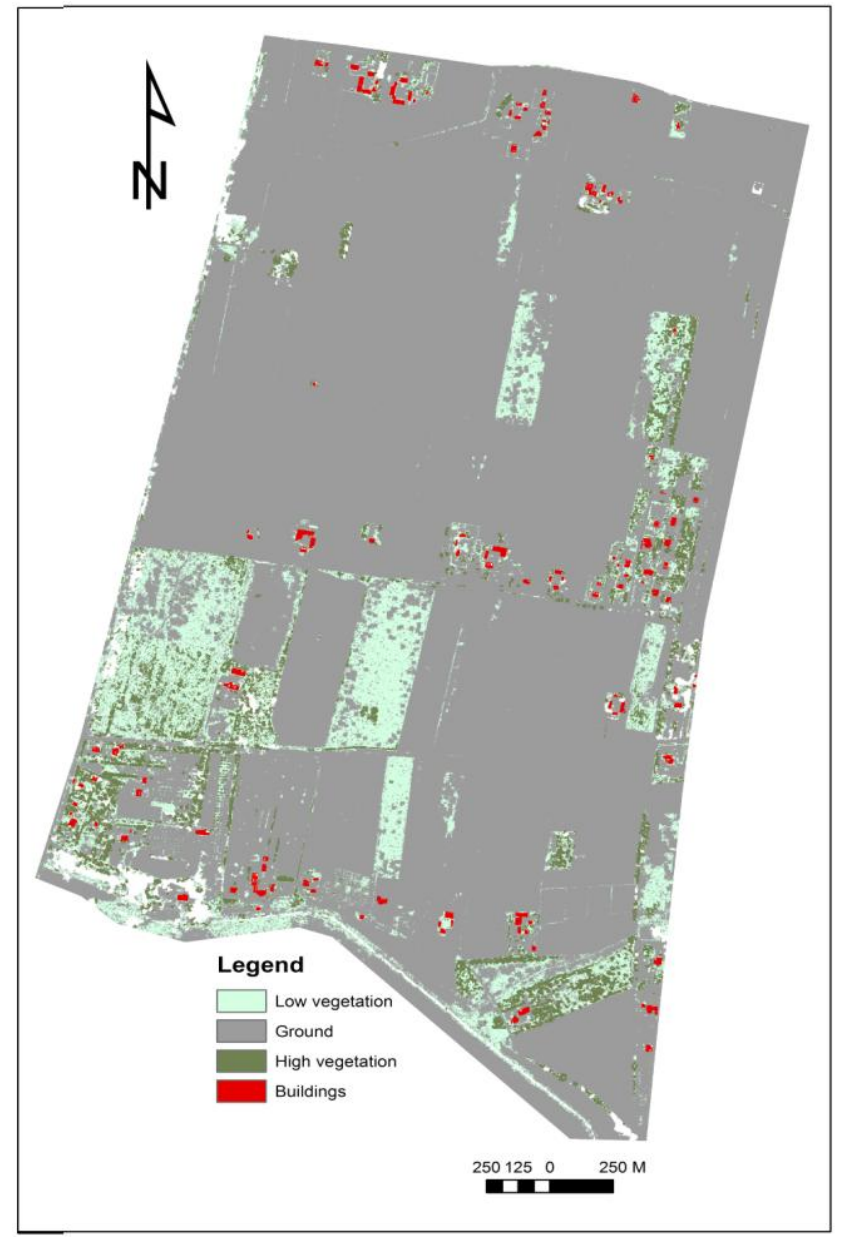

Figure. 1 A land cover map resulting from classification of a point cloud generated from dense image matching.

Additionally, classification of high vegetation and buildings was manually corrected using the ArcGIS software. The percent cover of lands of particular classes was determined based on statistical data. The largest area was "non-built-up" $(79.82 \%)$, followed by "low vegetation" (13.32\%), "high vegetation" $(8.32 \%)$, and "buildings" $(0.89 \%)$ (Fig.1).

Wetlands were identified based on UAV images; those areas characterized by dampness cover of $3.4 \%$ of the entire area. Using the drawing from Annex 2c of the Study of Conditions and Directions of Spatial Management of Kampinos Municipality, "Instrumentalisation of the spatial policy", areas where it is planned to create local plans were vectorized. As a result of combination of both analyses, areas excluded from development due to excessive dampness were determined. This is valuable information in the process of the creation of local plans for those areas, in particular where it is planned to develop housing districts following the conclusions of the Study (Fig. 2).

In order to control functions of buildings and types of roof, vectorization of buildings was performed at the first stage, based on true orthoimages. In order to correctly identify functions of buildings and types of roof (shed roofs, deck roofs, etc.), true orthoimages with a GSD of $3 \mathrm{~cm}$ were used.

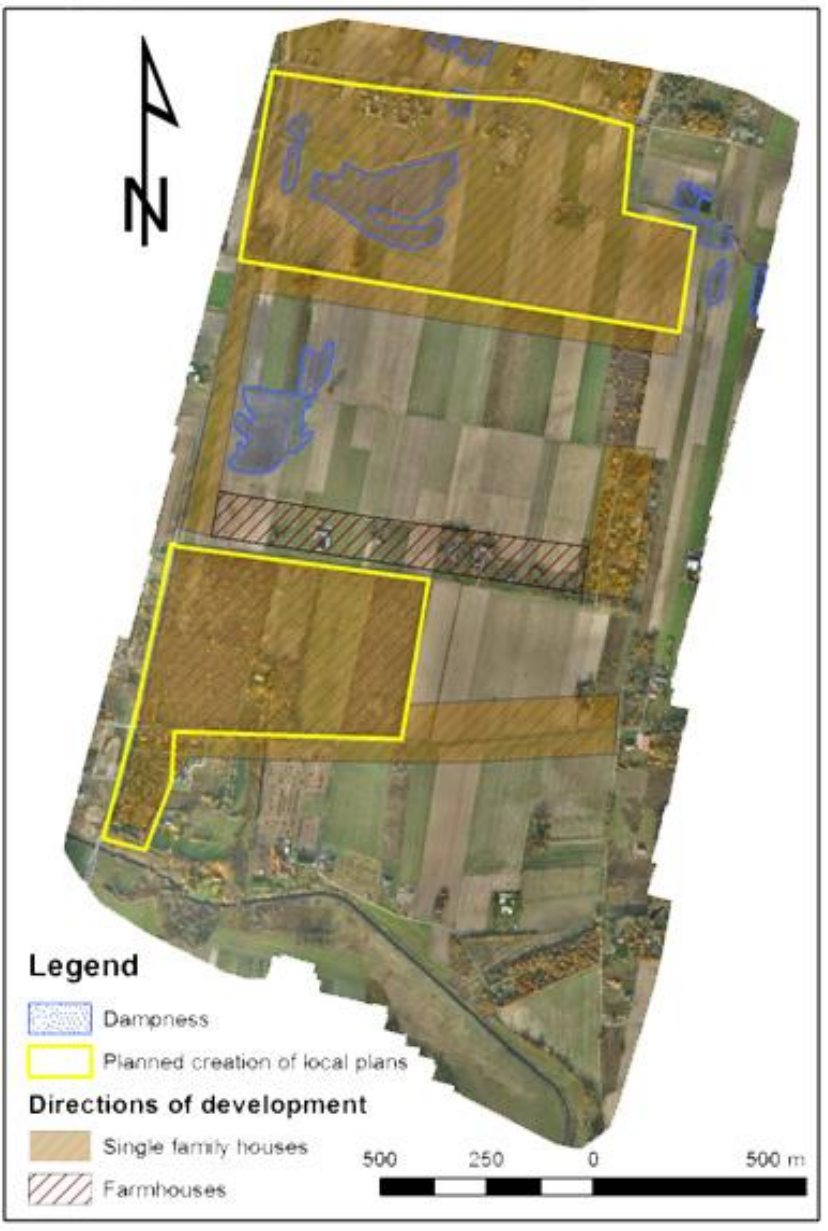

Figure. 2. Identification of areas excluded from development (extensively moist areas), areas to be covered by local management plans, and areas planned for single-family houses.

In the case of objects for which the type of roof could not be accurately determined, a 3D model (mesh form) was used to allow explicit identification of building functions and roof types. An example of the 3D mesh and true-ortho is presented in Fig. 3. Dense point clouds provide very good information about the shape and structure of buildings, and even wall textures. The product is very realistic and easily comprehensible and applicable.

During the classification process, 172 buildings were identified; half of these were residential. Most buildings (75\%) had gable roofs. Assuming $2.7 \mathrm{~m}$ as the floor height, about $15.7 \%$ were one-storey buildings; $51.2 \%$ were two-storey, and $33.1 \%$ threestorey buildings (important information when neighbourhood analysis is performed). Four buildings under construction were also identified based on the acquired photographs.

Based on the Study of Conditions and Directions of Spatial Management of Kampinos Municipality, areas of high natural value were identified, i.e., those which are environmentally protected or historical heritage areas (Fig. 4). Limited development of such areas can be planned for the future. 

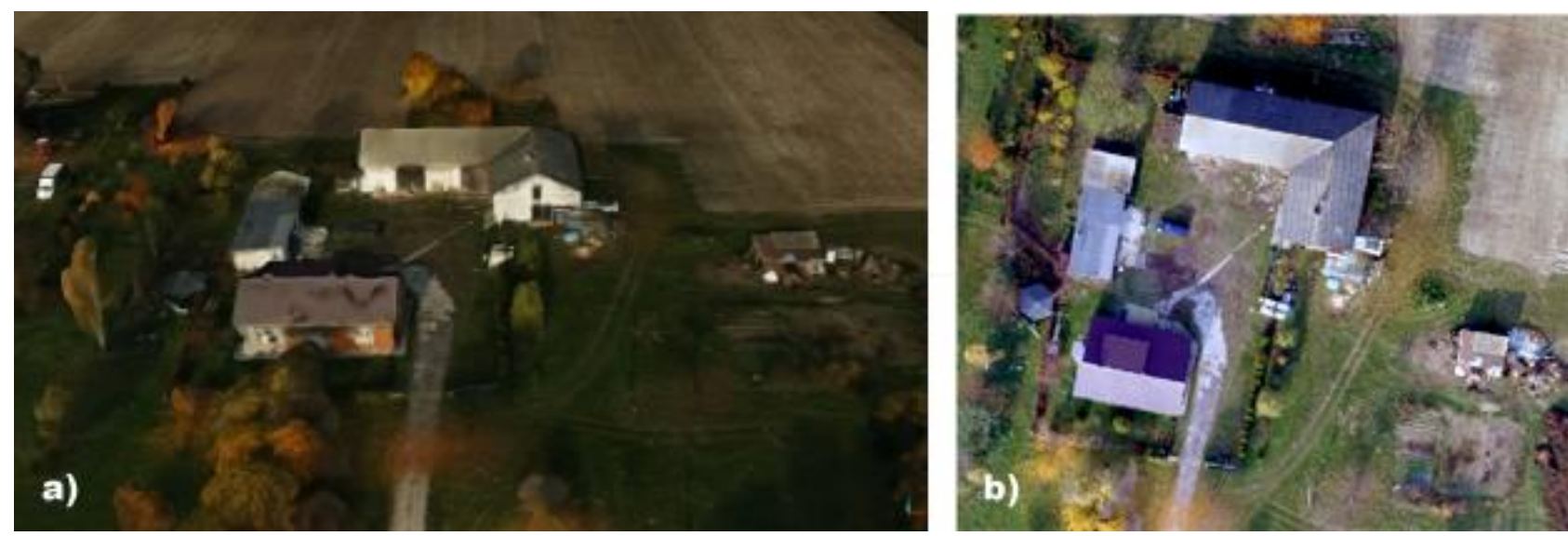

Figure. 3. Example of a) 3D mesh from dense-image-matching point cloud and b) part of the true-ortho

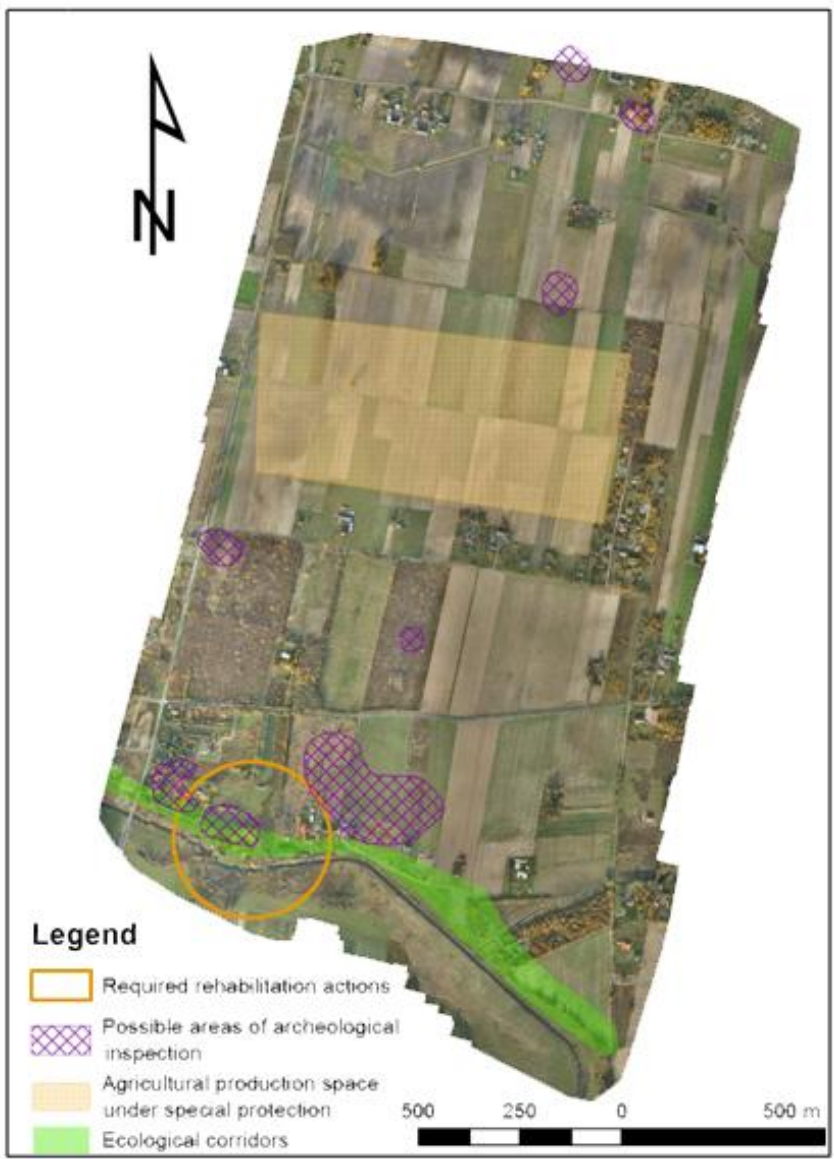

Fig. 4. Identification of areas of high natural value: environmentally protected and cultural heritage areas.

The next analysed aspect concerned the development of building sites. New buildings are constructed on arable lands, which are subject to division (Fig 5). Based on visible divisions of cadastral parcels, areas already prepared for construction of new buildings (delineated small parcels and access roads) were determined, suggesting the future trends of the dynamic development of building sites in the municipality.

The resulting map was created based on the performed analyses; it covers the areas excluded from development due to analysed features (Fig. 6.).

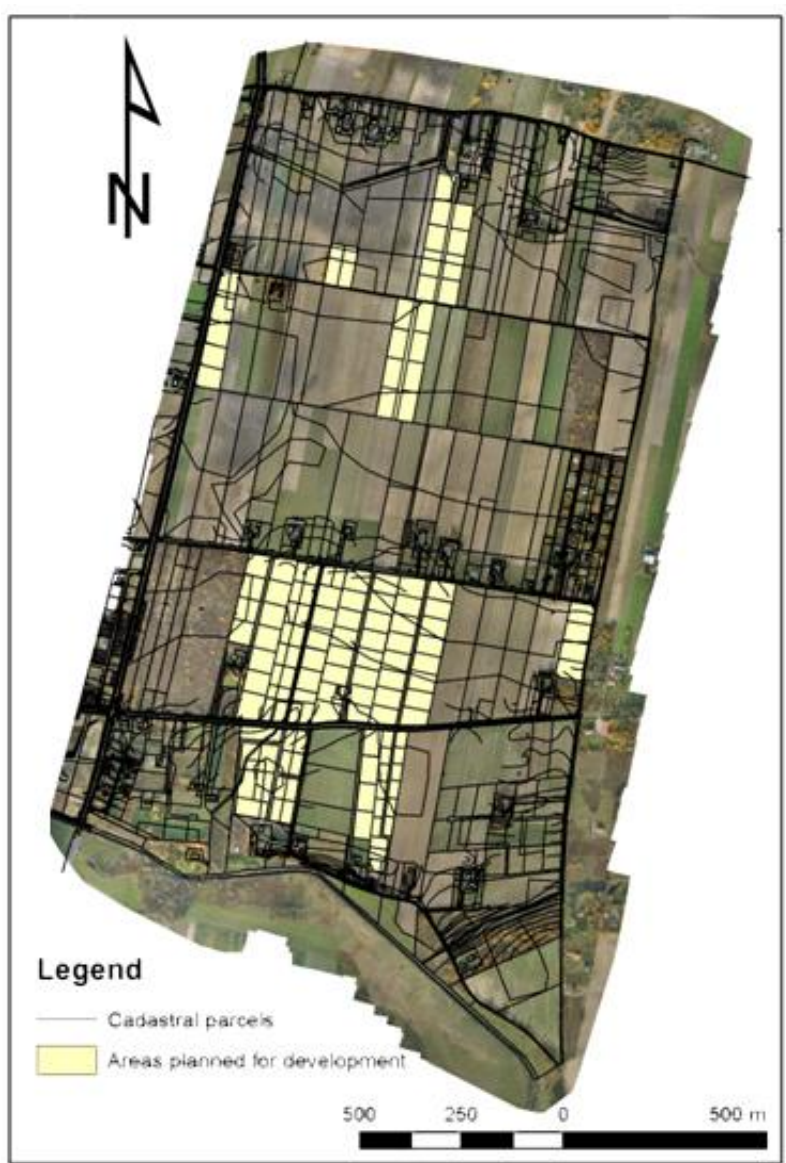

Figure.5. Parcels earmarked for future development.

This map clearly shows that new developments are planned on areas which, following the Study, should not be used for such purposes (in particular the agricultural production area should be excluded from any development), as well as on wetlands and areas where the natural and historical value has special protection. Two conflict areas were also delineated, where parcels for future development were planned and where the prohibition of development is included in the Study (the agricultural production area under particular protection). 


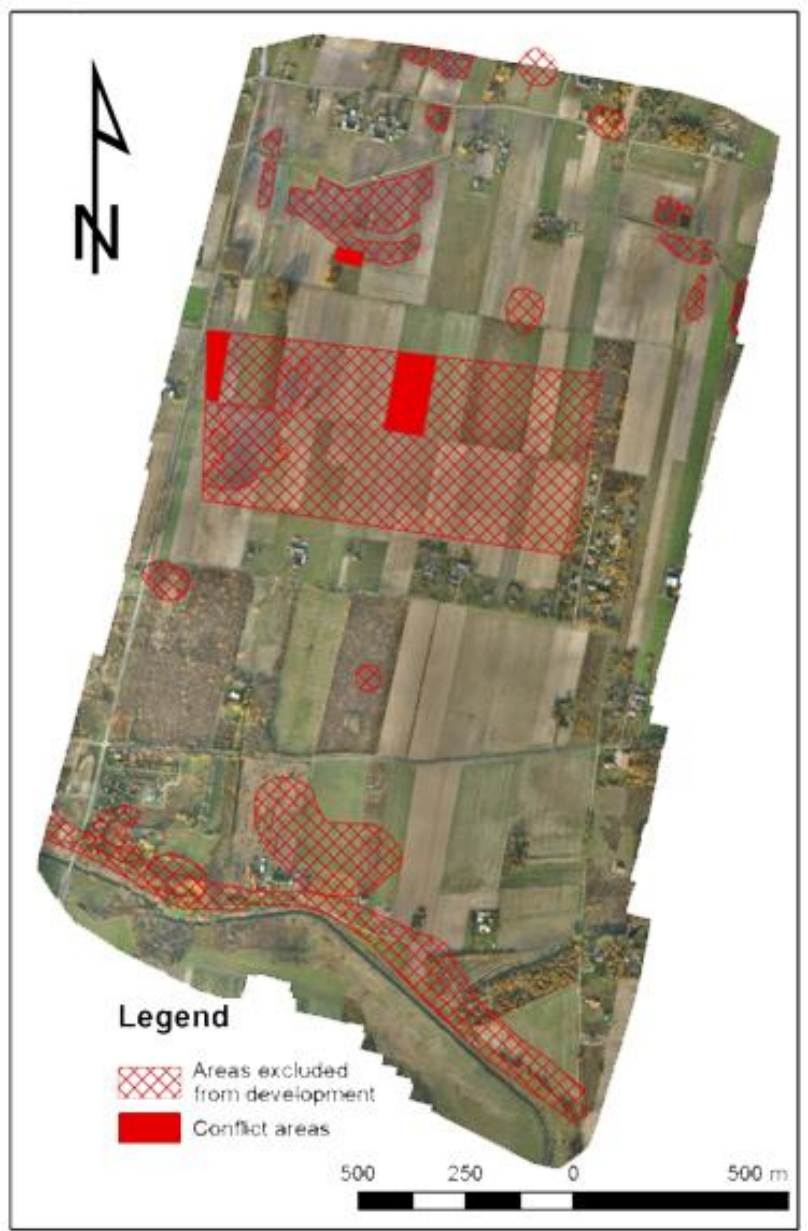

Figure 6. Areas excluded from development, including conflict areas.

The objective of the performed analyses was also to assess the possibilities of using multi-criteria analysis with lowaltitude photogrammetric data for spatial planning at the local and regional levels, in order to improve the quality and accelerate the process of sustainable development in the most effective and natural way.

\subsection{Evaluation of performed analyses with respect to spatial development of a selected municipality}

The binding Study of Conditions and Directions of Spatial Management of the Kampinos Municipality was adopted in 2008. Basic forms of use and the related rules and indices of development were applied to particular areas of the municipality. Areas of single-family housing with possible adaptation of existing farmhouses and development of recreational, service, and production facilities, with the exclusion of burdensome objects, predominate in the analysed area. Also prevalent are areas of agricultural production under special protection, whereby any development is forbidden. Other areas in the analysed fragment of the Podkampinos Village area include farmhouses and a manor-and-park area (located in the southern part of the analysed area). Adaptation operations are permitted in this site only with the consent of the Provincial Heritage Monuments Protection Office. This object is also marked as requiring rehabilitation operations, and the possible area of archaeological inspection has been delineated in its direct neighbourhood. Using UAV data, it is possible to generate a 3D model which may be used as a source material for further analyses and related decision-making.

The southern border of the analysed area is the Warsaw Protected Landscape Area. The northern part is the Kampinos National Park Buffer Zone (Study of Conditions and Directions of Spatial Management of the Kampinos Municipality, 2008). Updating of the Study is required, and the Kampinos municipal authorities are preparing for this at present. Implementation of appropriate spatial analyses with the use of UAV data is therefore justified, and can support local government authorities in making key planning decisions. Similarly, the two areas marked in the Study as "areas of planned creation of local spatial development plans" were identified. Although preparation of a local plan is not obligatory from the legal perspective, considering the existing conditions, development of such a document may be required for a fragment of the municipality. Such plans are prepared, first of all, in order to avoid negative impacts of land development changes on the spatial order or other protected values. The municipality may also decide that introduction of changes is required when social and economic aspects are considered; however, such changes cannot be introduced if a local spatial development plan is not created. This concerns areas where agricultural lands are planned to be used for non-agricultural purposes or forest lands destined to be used for non-forest purposes.

In areas subject to new divisions, mainly single-family houses are constructed. New buildings are constructed separately from the extant settlement structure in the direct neighbourhood, which comprises the cultural heritage of the municipality. $\mathrm{Ne}$ w buildings are located randomly or in groups along the borders of narrow parcels. In the case of urban areas, this situation is supported by regulations introduced by the Protection of Arable and Forest Lands Act, introduced in 2009, which simplify the process of making investments (e.g., building investments) in agricultural areas in cities. In the case of the analysed areas, new housing districts are being constructed based on divisions of real properties, often without the designed street network, required services, or consideration of the spatial arrangements. The planned use of long, narrow parcels, which were previously arable lands, as future building sites, will result in the introduction of new, strange forms into the landscape. The lack of rational development of areas planned as future building sites has a negative impact - although it is quite common. Introduction of housing functions in previously agricultural areas should follow the property and legal requirements of transformation, by means of processes of land consolidation and division of real properties. Land consolidation and divisions should be considered as required stages of change after adoption of the local plan (Bielska et al., 2013). The officially initiated procedure of land consolidation and division of real properties (borders of the area of land consolidation and real property division should be determined in the local plan of spatial development) will considerably improve the possibilities of area development, and will influence the landscape quality and therefore the local quality of life.

\section{CONCLUSIONS}

This paper has presented selected spatial analyses, showing the wide possibilities of applying low-altitude photogrammetric data permanently acquired with UAVs for updating planning documents. Such data may be used for creating inventories of an area without the necessity for planners to work in the field; this results in a considerable acceleration of the entire process. 


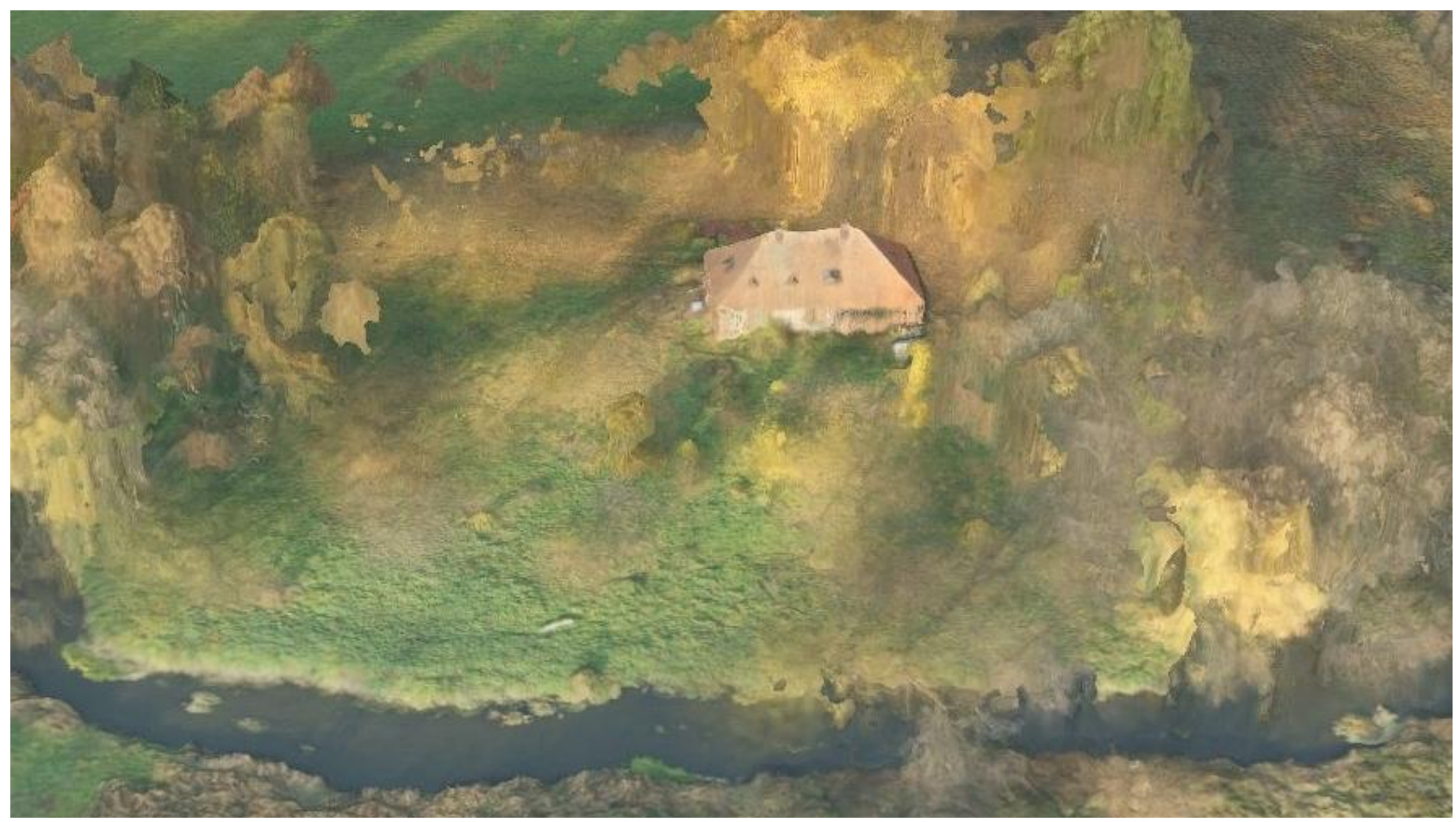

Figure. 7 The 3D model of Manor house and its surroundings

Unmanned aerial systems allow fast and precise acquisition of information, as well as "live" monitoring and measuring of large or difficult-to-access areas. 3D models generated based on images from UAVs are very useful products, which describe landscapes very realistically (Fig. 7). Multi-temporal photographs allow monitoring of changes in space, tracing the development of cities and thus the negative impacts of suburbanization (uncontrolled scattering of built-up areas) within suburban areas. Such documentation is also required for the assessment of possible locations of new investments. Within the analysed area, intensive development of single-family houses is planned. However, areas located in the north-western part of the area are characterized by a high level of dampness. Photogrammetric documentation based on UAV data allows assessment of soil moisture to assist consideration of the possibility of developing built-up areas. As a result, it is possible to evaluate locations of real estate and the possibilities of developing built-up areas, i.e., determining areas for future housing districts. UAV photographs may also be used to help determine the locations of power supply lines, which often generate conflicts due to inhabitants' concerns over such investments.

Unmanned aerial systems allow up-to-date and reliable information to be acquired, which may form a basis for planning decisions made by local government officials. Additionally, the participation of the community is required in the spatial planning process. At the consultations stage, true orthophoto images acquired by UAVs may be used instead of conventional maps and plans; these allow attractive and easy-to-use visualization of planned objects in the surroundings of the real neighbourhood. Such true orthophoto images also allow the creation of foundations for discussion and exchange of ideas between designers, local government officials, inhabitants, and entrepreneurs, which may contribute to the reduction of the time required for preparation of planning documents.

In rational spatial planning, it is important that the rulesCarr.and Zwick (2007). Smart land-use analysis : the LUCIS model : land-use conflict identification strategy, Redlands: ESRI Press specified in a study are considered. On the other hand, it is important to apply respective spatial analyses, which may be performed with the use of UAVs.

It is important to note that, in the case of spatial planning, UAVs are not only used to acquire data which describe the spatial municipal policy; data integration and alternative decisions, with consideration of the scope of performed and planned investments, are also important. Graphical presentation of the results of analyses, phenomena, and their distribution among inhabitants allows the inclusion of local societies in the spatial planning process. It also allows regular monitoring and co-ordination of the implementation of planned investments.

\section{ACKNOWLEDGEMENTS}

The authors would like to thank the MSP Company for their cooperation in the photogrammetric work, providing the UAV images used in the presented experiments.

\section{REFERENCES:}

Bakuła, K., Ostrowski, W., 2012. The application of non-metric digital camera in aerial photogrammetry on selected examples, Archives of Photogrannetry, Sartography and Remote Sensing, vol.24, pp. 11-20.

Bielska A., Barcikowska P., Witkowska M., 2013. Real property consolidation and partition as process supporting spatial planning on example of selected areas, $\mathrm{Nr}$ 2/III/2013, Polska Akademia Nauk, Oddział w Krakowie, Komisja Technicznej Infrastruktury wsi, pp. 17-26.

Chmielewski, J.M., 2010. Theory of city planning, Oficyna Wydawnicza Politechniki Warszawskiej, Warszawa. 
Degórska B., 2005. Acting against uncontrolled suburbanisation. Possibilities of national solutions with respect to approved European practices,. Urbanista, Warszawa.

H Carr M., Zwick P. D., 2007. Smart land-use analysis: the LUCIS model : land-use conflict identification strategy, Redlands : ESRI Press.

Kowalczyk, M., Podlasiak, P., Preuss, R. Zawieska, D., 2010. Evaluation of cartometric properties of true-ortho images, Archives of Photogrannetry, Sartography and Remote Sensing, Vol. 21, pp. 191-211.

Markiewicz J., Turek A, 2014. Application of multi-temporal aerial photographs to analysis of spatial management changes, Geodesic Review, nr 7, pp. 3-9.

Strecha, C., 2011. Automated photogrammetric techniques on ultra-light UAV imagery. Pix4D, http://www.pix4d.com/ downloads/pix4uav_accuracy.pdf, 1-11.

Study of Conditions and Directions of Spatial Management of the Kampinos Municipality, Warszawa, 2008.

Turek A., Markiewicz J. 2013 Possibilities To Integrate Photogrammetric Data For Selected Spatial Analyses, Annals of Geomatics, vol. 11, nr 3, pp. 95-10.4

Zimnicka A., Czernik L., 2007. Vademecum of a suburban village - the quality of space development, Hogben, Szczecin..

Zuziak Z.K.,.2005. Towards new architectonics of a city region, Urbanista, Warszawa. 